\title{
Bone grafting in dentistry
}

\author{
Shaik Ali Hassan ${ }^{1 *}$, Sumit Bhateja ${ }^{2}$, Geetika Arora ${ }^{3}$ \\ ${ }^{1}$ Dental Surgeon, ${ }^{2} \mathrm{HOD},{ }^{3}$ Reader, ${ }^{1}$ Dept. of Oral Medicine, ${ }^{3}$ Dept. of Public Health Dentistry, ${ }^{1,2}$ Manav Rachna Dental \\ College, Faridabad, Haryana, ${ }^{3}$ Inderprastha Dental College \& Hospital, Ghaziabad, Uttar Pradesh, India
}

\section{*Corresponding Author: Shaik Ali Hassan}

Email: alishaikhassan@gmail.com

\begin{abstract}
Recovery of the supporting structures of the teeth includes the utilization of an assortment of materials of normal and engineered causes. A definitive point of a genuine connective tissue connection to the cementum, be that as it may, is hard to accomplish and a couple of the materials have demonstrated promising outcomes. In this article we would like to give a idea of the grafting of bone.
\end{abstract}

Keywords: Grafting, Calvarial graft, Square bone block, Tibial bone.

\section{Introduction}

Bone deformities in the craniomaxillofacial skeleton change from the little (barely any millimeters) periodontal imperfections to the huge segmental deformities coming about because of injury, careful extraction, or cranioplasty. Such deformities regularly have complex three-dimensional auxiliary needs, which are hard to reestablish. In cranial vault surrenders, the basic mind needs lasting security. Segmental jaw abandons require rebuilding of mechanical respectability, temporomandibular joint practical and intermaxillary dental impediment. Keeping up satisfactory facial style is another special thought in the treatment of facial imperfections, which can't be thought little of. Bone unions remain the best quality level for remaking segmental bone deformities. We will review the status of bone joining systems for craniofacial reproduction, their natural foundation, as well as future headings. In 1881, Sir William MacEwen of Rothesay, Scotland, distributed the primary case report of effective interhuman move of bone grafts. ${ }^{1,2}$ He utilized tibial bone wedges extracted from three benefactors, during careful redress of skeletal distortion, to remake a humeral imperfection in a 3-year-old kid. Ensuing clinical reports built up the viability of autogenous bone unites in imperfection reconstruction. ${ }^{3,4}$

\section{Mechanism of action}

A bone join is characterized as any embedded material that advances bone recuperating, regardless of whether alone or in blend with other material. Growth of bone mending at the beneficiary site happens through at least one of the accompanying instruments: osteoconduction, osteoinduction, and osteogenesis. An osteoconductive material just permits, or coordinates, new bone arrangement along its surfaces. Models incorporate bone unite network and manufactured osteoconductive polymers. An osteoinductive join supplies enlistment as well as separation factors for bone-framing cells at the beneficiary site. An osteogenic join supplies initiated, or inducible, boneframing cells to the beneficiary site. In 1881, Sir William MacEwen of Rothesay, Scotland, distributed the principal case report of fruitful interhuman move of bone grafts. ${ }^{3,4} \mathrm{He}$ utilized tibial bone wedges extracted from three benefactors, during careful remedy of skeletal deformation, to remake a humeral imperfection in a 3-year-old kid. Resulting clinical reports built up the viability of autogenous bone joins in imperfection reconstruction. ${ }^{5}$

As needs be, a perfect bone unite is the one that capacities through every one of the three systems by giving a format that coordinates three dimensional bone development (osteoconduction), enrolls and incites separation of occupant bone-shaping cells, and supplies progressively bone-framing cells to the beneficiary site. Such joins incorporate cancellous and 
vascularized bone unions. Slow resorption is a burden if the unite is utilized to increase bone arrangement at the beneficiary site. Unite joining is contrarily corresponding to how strong the join is and how moderate it resorbs. ${ }^{6}$ Therefore, osteoconductive unite materials with interconnected inside spaces that arrive at the external surface are better platforms for coordinating three-dimensional bone intrusion of the join. This engineering gives increasingly surface zone along which local osteoclasts can append themselves and start dissolving the unite, which is the primary stage in join fuse.

\section{Sources of autogenous bone graft \\ Iliac Crest}

The iliac crest is one of the most widely recognized giver site for bone unions, both vascularized and nonvascularized. Enormous sections of cortical, corticocancellous, or cancellous bone can be immediately gotten for various estimated surrenders. Moreover, the area of the ilium permits reaping by a different careful group to spare activity time. A fullthickness iliac peak unite would have two thick cortices with abundant measure of trabecular bone in the middle of and can intently look like the thickness and stature of mandibular bone. The join shows sensible long haul endurance, and recovery with osseointegrated dental inserts is possible. ${ }^{7}$ Back iliac crest join can likewise be utilized for craniofacial recreation. Be that as it may, the patient must be tilted to the inclined position, which wipes out the benefit of a concurrent two-group approach. Benefactor site bleakness rate for foremost iliac peak joins is around $23 \%$, and substantially less for back iliac crest. ${ }^{8}$ Complications incorporate postoperative torment, iliac or acetabular breaks or flimsiness, steady hematoma, herniation of stomach substance, vascular damage, horizontal femoral cutaneous nerve damage, and unattractive shape surrenders along the iliac crest. ${ }^{9}$

\section{Calvariac Graft}

This is one of the most famous cortical bone unites in craniofacial recreation, basically for its mechanical properties and moderate resorption rate. ${ }^{10}$ This makes it perfect for facial increase, orbital rooftop and floor remaking, and covering cranial imperfections.
Ordinarily, just the external cortex is utilized, albeit a full-thickness unite could be taken and split into two unions. Regularly, the skull keeps on developing until the age of 8 , keeps on thickening until the age of 20 , and is thickest at the parietal district. This region can give $8 \times 10 \mathrm{~cm}$ of bone and is considered the most secure to harvest. ${ }^{11}$ The temporoparietal locale gives increasingly bended bone, which would be progressively appropriate for orbital or malar reconstruction.44 However, straight joins can be collected all the more posteriorly (i.e., from the occipitoparietal area). Regardless, the bone is regularly collected as tight strips (5 to $6 \mathrm{~cm}$ long 1.5 to $2 \mathrm{~cm}$ wide) to keep away from unite crack during harvest. At that point, a few strips can be fixed together and utilized as one join. Calvarial bone can be gathered at three levels: incomplete thickness external cortex, fullthickness external cortex, and bicortical. ${ }^{12}$ Partialthickness external cortex can be reaped utilizing an extremely sharp osteotome to twist off a sheet of cortical bone from the external cortical plate. This system can be utilized in youngsters between the age of 4 and 8 years and can yield enough issue that remains to be worked out a little deformity. In grownups, full-thickness external cortex can securely be gathered and is thusly the most ordinarily utilized calvarial unite. On the off chance that a craniotomy has just been performed, the inward cortex can be reaped from the bone fold and utilized in the reproduction, leaving the external cortex to be put back in its unique position. This procedure keeps up the form of the calvarium. On the off chance that huge amounts of bone are required, bicortical unions might be reaped, trailed by parting of the two cortices to two fold the outside of the unite. Clearly collecting a bicortical calvarial unite would have the most entanglements risk. Inconveniences of calvarial unites incorporate surface deformation at the contributor as well as beneficiary site and join break during harvest. Less ordinarily, dural introduction or tear can happen.

\section{Osseous Coagulum}

Intraoral bone, when gotten with high or low speed round brambles and blended in with blood turns into a coagulum. $^{13-15}$ It was along these lines shown in monkeys that little bone particles of 100 um could give 
a prior and more prominent osteogenic action than particles multiple times as enormous. ${ }^{16}$ The bone mix procedure was intended to beat a portion of the burdens of bony coagulum including powerlessness to suction during the assortment procedure and obscure quality and smoothness of the material. Bone mix is cortical or cancellous bone that is secured with a trephine or rongeurs, set in an amalgam container and triturated to the consistency of a slushy rigid mass.

\section{Square block like grafts}

Bone squares have the inborn bit of leeway of dependability and protection from distortion. They can be utilized for the flat expansion of alveolar bone deformities for periodontal recovery just as recreation of the alveolar bone for inserts and as a preprosthetic medical procedure for jaw remaking. Alveolar edge expansion is a need much of the time, which present in clinical practice to encourage sufficient bone volume for embed arrangement. The adjustment and personal contact of these square unites to the beneficiary bed have been viewed as vital to an effective result. This can be accomplished with the utilization of bone obsession screws or the concurrent arrangement of dental embed. Forceful beneficiary bed readiness with decortication, intramarrow infiltration, and decorate molding additionally has been upheld due to increments in the pace of revascularization, the accessibility of osteoprogenitor cells, and the expanded pace of renovating. The recuperating of autogenous square joins has been depicted as "crawling substitution" where practical bone replaces the necrotic bone inside the unite, and is profoundly reliant on unite angiogenesis and revascularization.

Square joins are collected as corticocancellous or cortical bone autografts. The revascularization of corticocancellous square joins happens at an a lot quicker rate than in cortical bone autografts and at a more slow rate than particulate autografts. Revascularization of square unites empowers the support of their imperativeness and henceforth, lessens odds of join disease and corruption. ${ }^{17,18}$

\section{Conclusion}

A broad research has been cultivated in the field of bone regenerative materials to improve their qualities, for example, mechanical quality, atomic creation, biocompatibility so as to take after highlights of common bone. With the progression of time, engineered inserts and different synchronous regenerative techniques substitute utilization of normal bone unions. The clinician should know about these substitutes and their properties to accomplish the most ideal clinical result for each specific patient. So the use of autogenous graft is the best.

\section{Source of Funding}

None.

\section{Conflict of Interest}

None.

\section{References}

1. Sculean A, Nikolidakis D, Nikou G, Ivanovic A, Chapple IL, Stavropoulos A. Biomaterials for promoting periodontal regeneration in human intrabony defects: A systematic review. Periodontol 2000. 2015;68:182-216.

2. Rosenberg E, Rose LF. Biologic and clinical considerations for autografts and allografts in periodontal regeneration therapy. Dent Clin North Am 1998;42:467-90.

3. Hegedus $Z$. The rebuilding of the alveolar process by bone transplantation. Dent Cosmos 1923;65:736-42.

4. Nabers CL, O'Leary TJ. Autogenous Bone Transplants in the treatment of osseous defects. J Periodontol 1965;36:514.

5. Linghorne WJ, O'Connell DC. Studies in the regeneration and reattachment of supporting structures of the teeth. II. Regeneration of alveolar process. J Dent Res 1951;30:60414.

6. Burwell RG. Studies in transplantation of bone. $J$ Bone $J t$ Surg 1964;48-B:532.

7. Rivault AF, Toto PD, Levy S, Gargiulo AW. Autogenous bone grafts: Osseous coagulum and osseous retrograd procedures in primates. J Periodontol 1971;42:787-96.

8. Steringa B. Studies of the vascularization of bone grafts. $J$ Bone Joint Surg 1957;46B:395.

9. Schallhorn RG. The use of autogenous hip marrow biopsy implants for bony crater defects. J Periodontol 1968;39:145-7.

10. Sullivan H, Vito A, Melcher A. A histological evaluation of the use of hemopoietic marrow in intrabony, periodontal defects. Int Assoc Dent Res (Abstracts) 1971;171.

11. Dragoo MR, Sullivan HC. A clinical and histologic evaluation of autogenous iliac bone grafts in humans. II. External root resorption. J Periodontol 1973;44:614-25.

12. Schallhorn RG, Hiatt WH, Boyce W. Iliac transplants in periodontal therapy. J Periodontol 1970;41:566-80. 
13. Hiatt WH, Schallhorn RG. Intraoral transplants of cancellous bone and marrow in periodontal lesions. $J$ Periodontoal 1973;44:194-208.

14. Froum SJ, Thaler R, Scopp IW, Stahl SS. Osseous Autografts. I. Clinical responses to bone blend or hip marrow grafts. J Periodontol 1975;46:515-21.

15. Froum SJ, Ortiz M, Witkin RT, Thaler R, Scopp IW, Stahl SS. Osseous Autografts. III. Comparison of osseous coagulum-bone blend implants with open curettage. $J$ Periodontol 1976;47:287-94.

16. Moskow BS, Karsh F, Stein SD. Histological assessment of autogenous bone graft: A case report and critical evaluation. J Periodontol 1979;50:291-300.
17. Myeroff C, Archdeacon M. Autogenous bone graft: Donor sites and techniques. J Bone Joint Surg Am 20117;93:222736

18. Mellonig JT. Autogenous and allogeneic bone grafts in periodontal therapy. Crit Rev Oral Biol Med 1992;3:33352.

How to cite this article: Hassan SA, Bhateja S, Arora G. Bone grafting in dentistry. J Paediatr Nurs Sci 2019;2(4):108-111. 